\title{
Acquired immune deficiency syndrome case reporting system - Addressing the problem of reporting delay
}

Don Sutherland, MD, Maura Ricketts, MD, PING YAN, PhD

$\mathrm{T}$ HE LABORATORY CENTRE FOR DISEASE CONTROL'S (LCDC) acquired immune deficiency syndrome (AIDS) Case Reporting Surveillance System (ACRSS) has been recording reports of AIDS since 1982. The first known case of AIDS in Canada was diagnosed in 1979 and was reported retrospectively.

AIDS is reportable to the provincial or territorial medical officer of health $(\mathrm{MOH})$ under public health acts in every province and territory. The diagnosis and initial report of an AIDS case is made by the patient's health care provider, usually the physician. Each province and territory issues health care providers with an AIDS case report form. The clinician sends the report form to the local $\mathrm{MOH}$ (who forwards the report to the provincial $\mathrm{MOH})$. Provincial MOHs send copies of the completed reports to LCDC, where a national data set is maintained.

By October 1, 1992, LCDC had received 6889 AIDS case reports. In the early 1980 s, reports of AIDS cases were unusual, but after 1985 the number of reports began to increase dramatically. This increase was maintained until 1988, when an apparent levelling of reported cases occurred.

As Figure 1 reveals, fewer reports were received in 1991 and 1992 than in the previous three years. The

Correspondence and reprints: Dr D Sutherland, HIV/AIDS Division, Bureau of Communicable Disease Epidemiology. Laboratory Centre for Disease Control, Tunney's Pasture, Ottawa, Ontario K1A OL2. Telephone (613) 957-1777, Fax (613) 954-5414 conclusion that the epidemic of AIDS cases has levelled off - and may actually be declining - is an erroneous and premature interpretation of these data.

There are two important aspects of surveillance which must be clarified before an accurate interpretation of trend can be made.

- 'Reporting delay' is defined as the time between AIDS diagnosis and the reception of the completed case report at LCDC. Based on past experience, reporting delay can be calculated and a model created which will project how many more reports of AIDS will be received. Reporting delay adjustments commonly are applied to longitudinal data sets. The Division of Human Immunodeficiency Virus (HIV)/AIDS Epidemiology recently has developed a model of reporting delay for ACRSS.

- Reporting completeness or under-reporting is defined as the proportion of the true number of cases which is received by the surveillance system. There are two components to underreporting. Some cases of AIDS are never diagnosed and, hence, never reported (this number is unknown). The second component consists of cases which are recognized but not reported to ACRSS. This number can be estimated through record linkage with other sources of AIDS data, such as AIDS cohorts or death certificates, In Canada, we estimate $15 \%$ of cases are under-reported (1). 


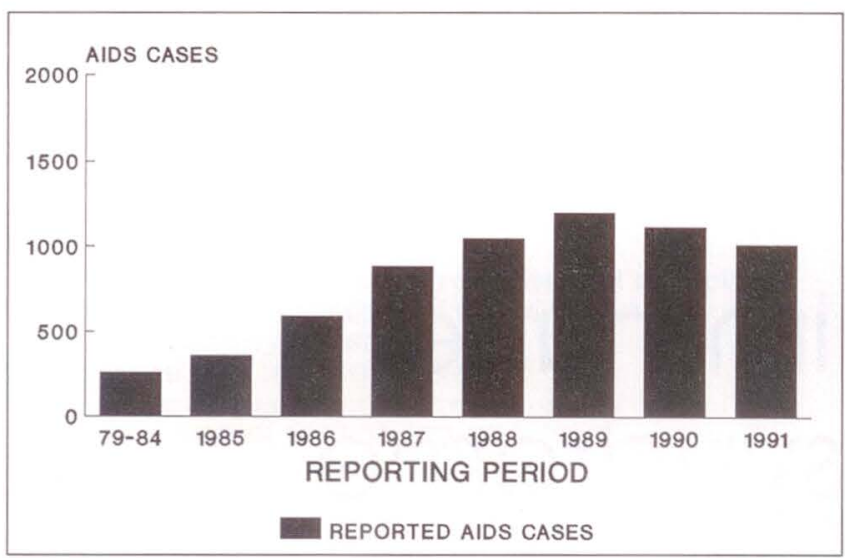

Figure 1) Trend in reported acquired immune deficiency syndrome (AIDS) cases in Canada: cases by year of diagnosis

Delayed reporting and under-reporting are universal problems for AIDS surveillance. A recent report from Switzerland (2) indicated an under-reporting rate of $32 \%$; other developed countries indicate similar rates.

When reported cases are adjusted for both delay in reporting and under-reporting, the shape of the epidemic curve indicates that there is no decline in AIDS cases (Figure 2).

It currently is estimated that the number of prevalent HIV infections in Canadians is approximately 30,000 (3). Given the burden of HIV infection in Canada and a better understanding of the corrections to the AIDS epidemic curve, there will be no decline in AIDS cases in Canada in the near future.

Planning for AIDS/HIV care and prevention is based on the collection, analysis and interpretation of good

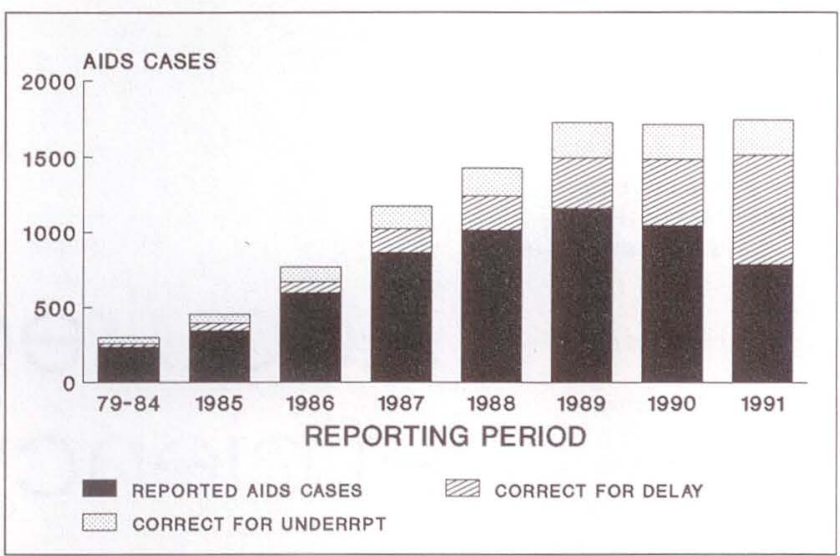

Figure 2) Trend in acquired immune deficiency syndrome (AIDS) cases in Canada adjusted for delay and under-reporting

data. The data on AIDS cases are extremely dependent on the cooperation of primary care doctors and nurses, consulting physicians and the medical officers of health in communities throughout Canada. We encourage a renewed effort to keep the data relevant and accurate.

\section{REFERENCES}

1. Calzavara LM, Coates RA, Craib KJP, et al.

Underreporting of AIDS cases in Canada: A record linkage study. Vth International Conference on AIDS. Can Med Assoc J 1990;142:36-9.

2. Engel RR, Samuel MC, Rieder HL, Billo N, Somaini B. Completeness of AIDS reporting in Switzerland: A study based on deaths between December 1987 and June 1990. AIDS 1992;6:1385-9.

3. Remis RS, Sutherland WD. The epidemiology of HIV and AIDS in Canada: Current perspectives and future needs. Can J Public Health. (In press) 


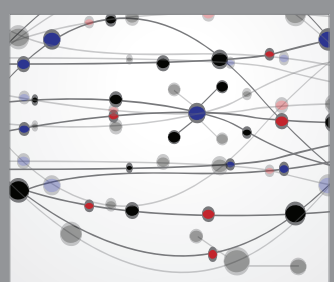

The Scientific World Journal
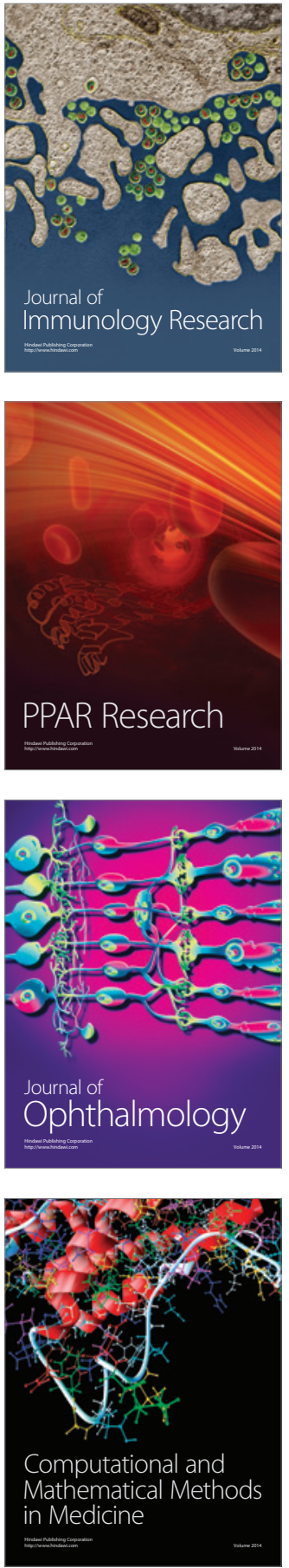

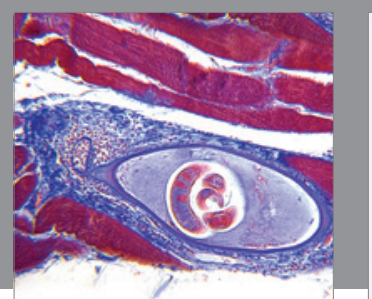

Gastroenterology Research and Practice

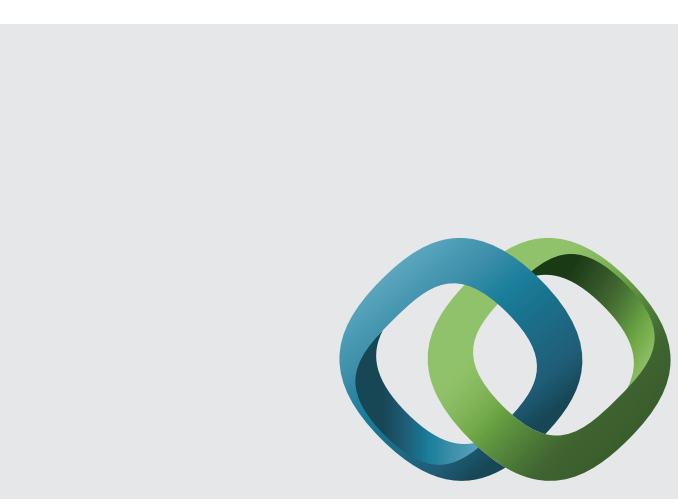

\section{Hindawi}

Submit your manuscripts at

http://www.hindawi.com
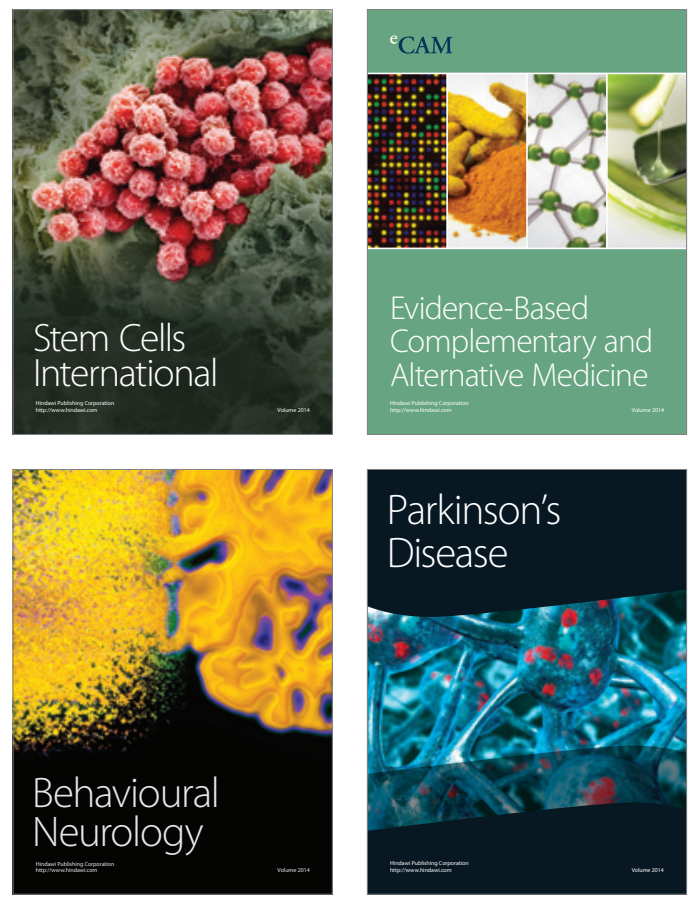
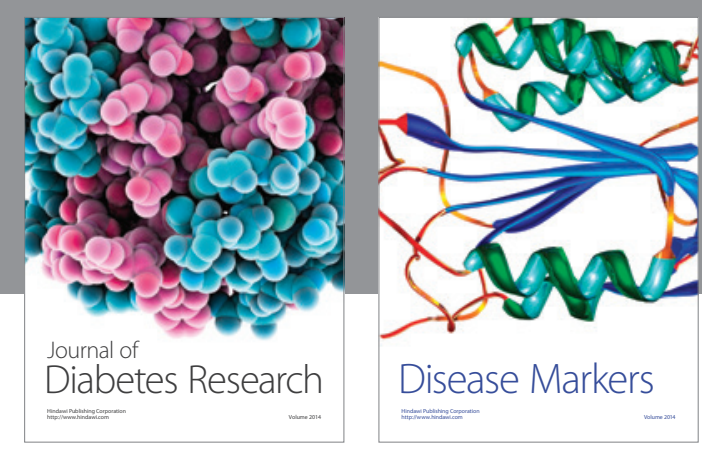

Disease Markers
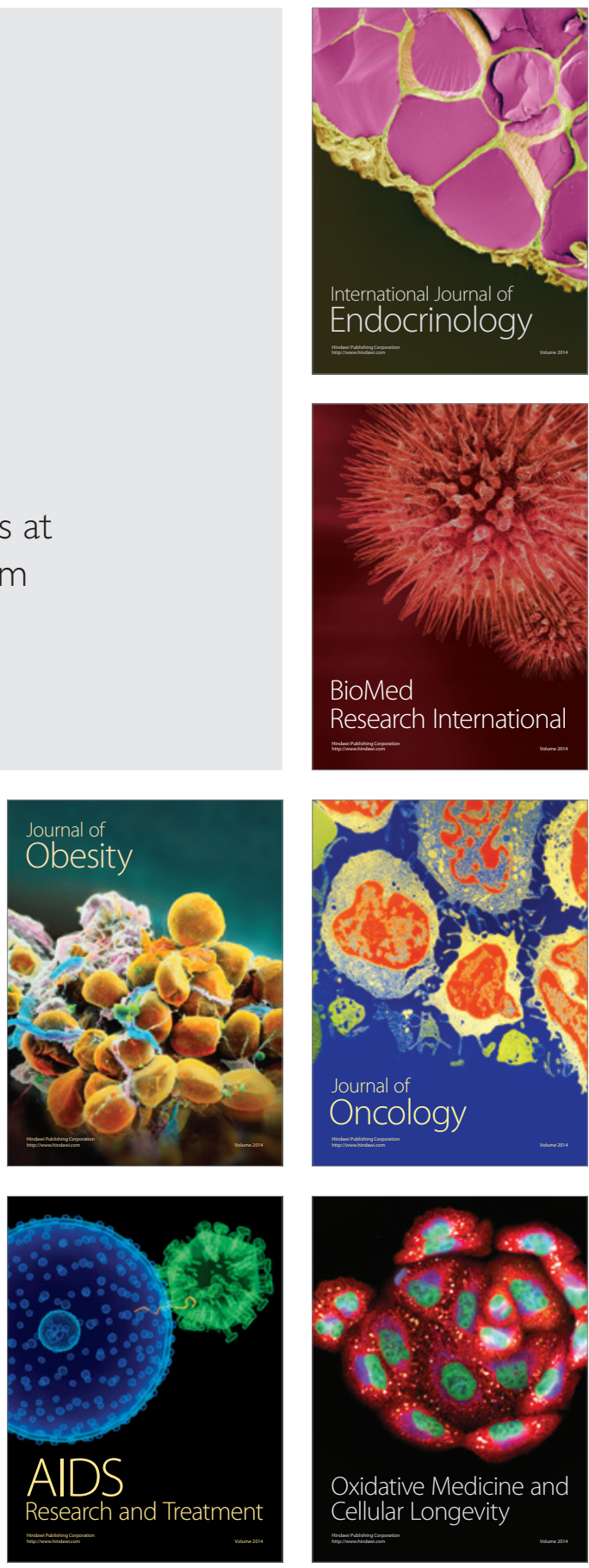